\title{
Effects of forest conversion and seasonal changes on the assembly of bacterial and fungal communities in tropical forests
}

\author{
G Lan ${ }^{1}$, Bangqian Chen ${ }^{2}$, Zhixiang $\mathrm{Wu}^{3}$, Chuan Yang ${ }^{3}$, and Xicai Zhang ${ }^{2}$ \\ ${ }^{1}$ Rubber Research Institute, Chinese Academy of Tropical Agricultural Sciences \\ ${ }^{2}$ Rubber Research Institute, Chinese Academy of Tropical Agricultural Sciences \\ ${ }^{3}$ RRI,CATAS
}

September 25, 2021

\begin{abstract}
To date, few studies have assessed the impact of forest conversion or seasonal changes on soil microbial community assembly. To fill this research gap, 16S rRNA and ITS gene sequences were used to evaluate the effects of forest conversion and seasonal changes on the assembly of bacterial and fungal communities using 260 soil samples collected from tropical rainforest and rubber plantation sites across Hainan Island, South China. A majority ( $60 \%$ ) of observed OTUs conformed with neutral model expectations, indicating that neutral processes were important for the assembly of soil microbial communities. For bacterial communities, the NST (normalized stochasticity ratio) was higher in the tropical rainforest (0.746 in the dry season, 0.684 in the rainy season) versus rubber plantation sites $(0.647,0.584)$, regardless of season. Thus, forest conversion decreased the importance of stochasticity for soil bacterial community assembly. For fungal communities, rubber plantation communities showed greater stochasticity $(\mathrm{NST}=0.578)$ than rainforest communities $(\mathrm{NST}=0.388)$ in the dry season, but the reverse was true in the rainy season (NST $=0.852$ for rubber plantations; NST $=0.978$ for rainforest). Both the NST results and structural equation modeling showed that bacterial communities were more stochastic in the dry season, while fungal communities were more stochastic in the rainy season; the effects of seasonal changes on assembly therefore differed between bacterial and fungal communities. More importantly, forest conversion did not have a direct impact on the assembly of bacterial or fungal communities, but exerted indirect effects via soil $\mathrm{pH}$ and soil $\mathrm{AK}$.
\end{abstract}

\section{Hosted file}

Effects of forest conversion on the assembly.doc available at https://authorea.com/ users/315668/articles/538811-effects-of-forest-conversion-and-seasonal-changes-on-theassembly-of-bacterial-and-fungal-communities-in-tropical-forests 